\title{
Predictive Factors for Hepatocellular Carcinoma Development after Direct-Acting Antiviral Treatment of HCV
}

\author{
Zuzana Macek Jilkova ${ }^{1,2,3, * \mathbb{C}, \text { Komal Saleem }}{ }^{4}$, Samia Afzal ${ }^{4}\left(\mathbb{D}\right.$ and Thomas Decaens ${ }^{1,2,3}$ (D) \\ 1 Université Grenoble Alpes, 38000 Grenoble, France; tdecaens@chu-grenoble.fr \\ 2 Institute for Advanced Biosciences, Research Center Inserm U1209 CNRS UMR5309, 38700 La Tronche, France \\ 3 Service D'Hépato-Gastroentérologie, Pôle Digidune, CHU Grenoble Alpes, 38700 La Tronche, France \\ 4 Centre of Excellence in Molecular Biology, University of The Punjab, Lahore 54000, Pakistan; \\ komalsaleem12@gmail.com (K.S.); samiaraza@live.com (S.A.) \\ * Correspondence: zmacekjilkova@chu-grenoble.fr
}

Citation: Macek Jilkova, Z.; Saleem, K.; Afzal, S.; Decaens, T. Predictive Factors for Hepatocellular Carcinoma Development after Direct-Acting Antiviral Treatment of HCV. Livers 2021, 1, 313-321. https://doi.org/ $10.3390 /$ livers 1040024

Academic Editor:

Alessandro Federico

Received: 30 October 2021

Accepted: 6 December 2021

Published: 14 December 2021

Publisher's Note: MDPI stays neutral with regard to jurisdictional claims in published maps and institutional affiliations.

Copyright: () 2021 by the authors. Licensee MDPI, Basel, Switzerland. This article is an open access article distributed under the terms and conditions of the Creative Commons Attribution (CC BY) license (https:// creativecommons.org/licenses/by/ $4.0 /)$.

\begin{abstract}
Chronic hepatitis $C$ virus infection is still one of the major risk factors for the development of hepatocellular carcinoma (HCC), the most frequent type of primary liver cancer. Direct-acting antivirals have substantially improved the cure rate of the virus, but the risk of hepatitis $C$ virusrelated HCC remains high, mainly in patients with advanced liver fibrosis and cirrhosis. HCC is often asymptomatic and, therefore, remains undetected until the late tumor stage, which is associated with poor survival rates. Therefore, to improve the surveillance programs following HCV eradication, there is a need to summarize predictive factors or potential biomarkers, to specifically identify patients likely to develop HCC after direct-acting antiviral treatment. This review outlines the most recent data about different predictive factors for HCC development after direct-acting antiviral treatment of hepatitis $C$ virus-infected patients, to improve the clinical management of patients with chronic hepatitis $\mathrm{C}$ virus.
\end{abstract}

Keywords: HCV; HCC; DAA; liver; predictive factors

\section{Introduction}

Primary liver cancer is now the sixth most frequently diagnosed type of cancer and the third leading cause of cancer-related mortality [1], with hepatocellular carcinoma (HCC) accounting for up to $85 \%$ of all primary liver cancer cases. HCC develops almost exclusively with a background of chronic hepatic inflammation, which is mainly caused by viral hepatitis, chronic alcohol consumption, or an unhealthy diet.

Chronic hepatitis $\mathrm{C}$ virus (HCV) infection is one of the major risk factors in the development of HCC. It is caused by the capacity of HCV to evade the host's immune system in approximately $80 \%$ of patients [2]. Chronic HCV infection induces, not only persistent epigenetic alterations [3], but also misbalances the liver immune microenvironment [4-6], which leads to serious, irreparable liver damage.

$\mathrm{HCV}$ is a virus with a positive-strand RNA, which belongs to the Hepacivirus genus, within the virus family Flaviviridae. Despite the high global prevalence of infection by $\mathrm{HCV}$, estimated at $2.5 \%$ of the world population [7], the first hope for the elimination of $\mathrm{HCV}$ worldwide appeared recently. Thirty-two years after the discovery of HCV [8], the understanding of its virological features, worldwide epidemiology, and, mainly, recent antiviral therapeutic developments have raised the prospect of its global eradication. Indeed, direct-acting antiviral (DAA) agents against HCV infection have been a remarkable success. This has been demonstrated by complete viral eradication in up to $95 \%$ of $\mathrm{HCV}$ patients. The successful fight against HCV even garnered a Nobel Prize in Physiology or Medicine in 2020 for Dr. Harvey Alter, Dr. Charles Rice, and Dr. Michael Houghton, for their important contributions to the identification and characterization of the virus [9]. 
Even though the introduction of DAA therapies has significantly changed the landscape of HCV, the risk of HCV-related liver cancer remains high, mainly in patients with advanced liver fibrosis and cirrhosis [10-12]. Indeed, antiviral treatment among HCVinfected individuals reduces, but does not prevent, de novo HCC development [13,14]. Moreover, the risk of HCC recurrence seems to be almost unaffected by HCV elimination [15]. Thus, one of the biggest future challenges will be the early diagnosis of HCC development after DAA treatment. The main complication of early diagnosis of HCC is that it is often asymptomatic and, consequently, remains undetected until the late tumor stage. Thus, there is a need to summarize the predictive factors or potential biomarkers that could help predict HCC risk, by identifying patients likely to develop cancer and including them in surveillance programs. In this brief review, we provide the most recent data pertaining to possible predictive factors and biomarkers for HCC development after DAA treatment of chronic HCV patients, Figure 1.

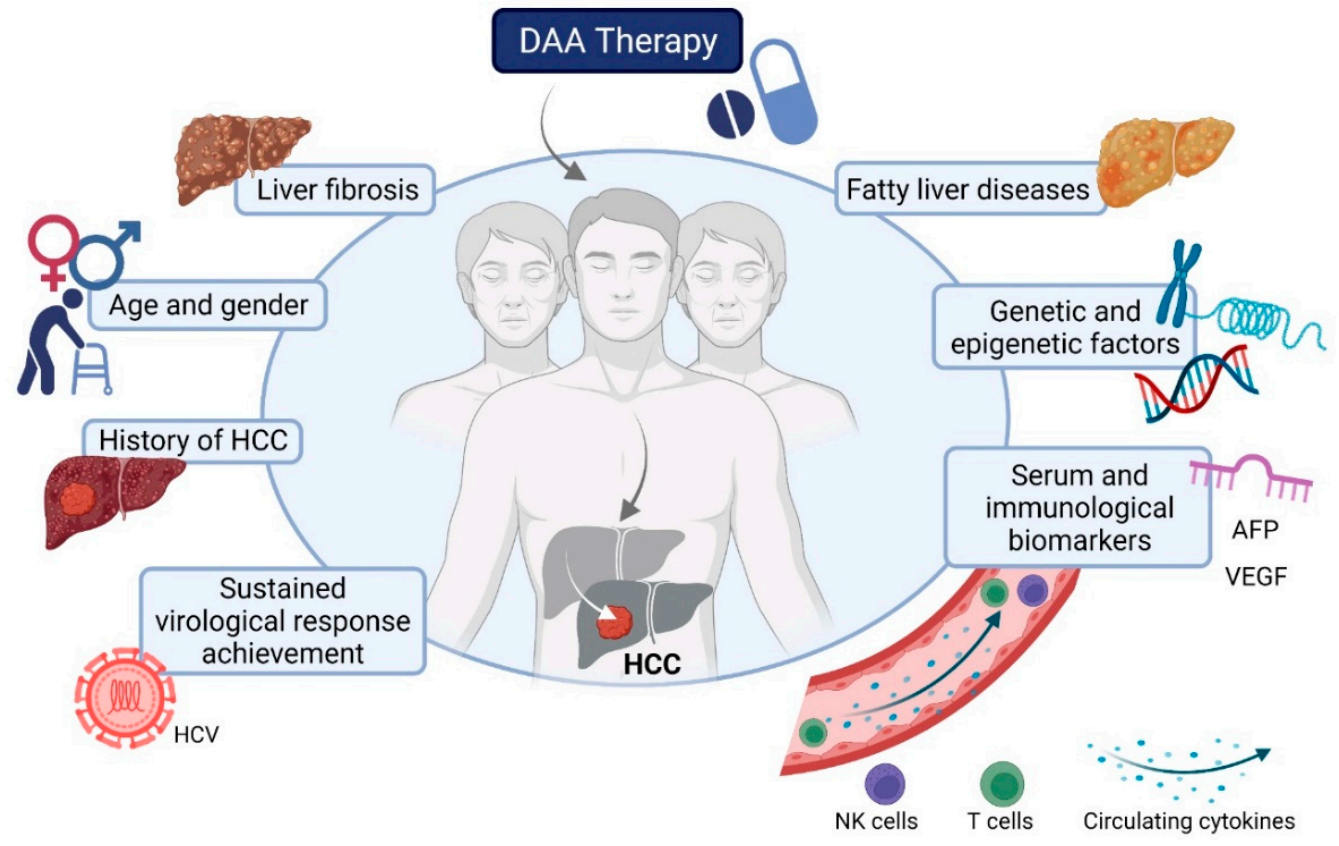

Figure 1. Predictive factors for hepatocellular carcinoma (HCC) development after direct-acting antiviral treatment of $\mathrm{HCV}$.

\section{Predictive Factors and Biomarkers for HCC Development after DAA Treatment of HCV}

\subsection{Sustained Virological Response Achievement}

Sustained virological response, induced by DAA treatment, is associated with a reduction in HCC risk in the medium and long term, while failure to achieve a sustained virological response is strongly linked with development of HCC, as demonstrated previously [16-20]. Prospective and retrospective studies investigating the link between the occurrence of HCC and sustained virological response induced by DAA treatment were recently summarized elsewhere [12].

\subsection{History of HCC}

A history of previous HCC is another well-known factor strongly associated with the development of HCC after DAA treatment of HCV. A recent meta-analysis found that the HCC recurrence in patients with HCC history is considerably high after DAA therapy (about $30 \%$ of patients), particularly, soon after the termination of DAA treatment [14].

In addition, dysplastic nodule occurrence before starting DAA therapy was associated with early HCC within 1-year of treatment of HCV [21]. Similarly, Mario et al. demonstrated 
that the risk of HCC development after DAA treatment was significantly increased in patients with hepatic nodules at baseline in a cohort of cirrhotic HCV patients [22].

\subsection{Age and Gender}

Patient demographic parameters such as advanced age are known to be linked with HCC development after HCV eradication [23]. For instance, a recent study revealed that cumulative HCC incidence was increased in the 75-84-year age group, compared to those 60-74 [24]. Aside from age, male gender $[23,25]$ and patient lifestyle, including smoking and alcohol consumption, are risk factors for HCC development after sustained virological response achievement [11].

\subsection{Liver Fibrosis}

As mentioned before, DAA-induced $\mathrm{HCV}$ elimination does not eradicate the risk of HCC development, especially among chronically infected HCV patients with advanced liver fibrosis and cirrhosis. This is not surprising, as this therapy does not immediately revert the underlying pathology of liver, even though sustained virological response can reduce fibrosis progression or even stimulate fibrosis regression. However, higher liver fibrosis stages are usually associated with a lower reversibility potential [26]. Thus, liver fibrosis prior to treatment is definitely one of the most important predictive factors for HCC development after DAA treatment [12].

Consistent evidence demonstrates that liver stiffness measurement (LSM) can be used as a non-invasive marker, helping to predict HCC development after DAA treatment in cirrhotic patients. Indeed, several studies have evaluated this predictive marker using different LSM threshold levels to discriminate HCC risk in HCV patients at various stages of cirrhosis [23,27-32]. A recent meta-analysis confirmed the predictive value of LSM for HCC development in DAA-treated patients [33].

Similarly, the liver fibrosis 4 index (FIB-4), a noninvasive test combining classical biochemical values (AST, ALT, platelets) and the age of HCV patients, can be used to predict whether a patient is at higher risk of developing HCC after sustained virological response. In particular, among HCV-infected patients who had achieved a sustained virological response after antiviral treatment, a FIB-4 score higher than 3.25 identified the high-risk population. Importantly, an FIB-4 score higher than 3.25 could serve as a predictive factor, even in the non-cirrhotic patient group [34,35].

\subsection{Serum Biomarkers: AFP and Others}

Alpha fetoprotein (AFP) is the main circulating biomarker used clinically as a prognostic and diagnostic factor for HCC. However, AFP is sub-optimally effective in the early detection of HCC. AFP circulating levels show a wide variation in specificity and sensitivity, among others reasons due to elevated levels of AFP in liver diseases, including viral hepatitis. Nevertheless, AFP has been identified as a possible predictive factor for HCC development after DAA treatment. Tanaka et al. reported that among both cirrhotic and non-cirrhotic DAA-treated patients who achieved a sustained virological response, baseline AFP levels ( $\geq 10 \mathrm{ng} / \mathrm{mL}$ ) were significantly associated with higher HCC risk [36]. Similarly, a recent study revealed that patients with higher post-treatment AFP had a high risk of recurrence of HCC [37]. In line with these findings, several other studies have confirmed AFP as a circulating biomarker associated with HCC development after DAA treatment [38-40].

Furthermore, low levels of albumin and low platelet count were associated with higher incidence of HCC in cirrhotic HCV patients treated by DAA [20,32,39].

Another serum marker that could help identify chronic HCV patients at high risk of do novo HCC is the serum level of Wisteria floribunda agglutinin-positive Mac-2 binding protein (WFA+ -M2BP), as identified recently by Yasui et al. in a cohort of Japanese patients [40]. In addition, serum sphingolipids were proposed as possible biomarkers that can help identify patients at risk of de novo HCC development after DAA treatment. 
Specifically, Mücke et al. described C16Cer as an early biomarker in a cohort of cirrhotic $\mathrm{HCV}$ patients [41].

Furthermore, Faillaci et al. proposed that the DAA-induced increase of circulating VEGF could be responsible for HCC development after DAA treatment, mainly in predisposed patients [42]. Similarly, Ramadan et al. showed that serum VEGF levels were significantly increased in those $\mathrm{HCV}$ patients treated with DAA and developing HCC, as compared to those who did not receive DAA therapy [43].

\section{6. $m i R N A$}

Another promising circulating biomarker for HCC development after DAA treatment could be based on microRNA (miRNA) profile. Indeed, Pascut et al. identified circulating miR-3197 as a possible biomarker, identifying patients who could develop early HCC following DAA treatment [44]. Importantly, differences were observed, even before the initiation of treatment, suggesting that some chronic HCV-infected patients might already be susceptible to HCC development before DAA therapy.

\subsection{Underlying Metabolic-Associated Fatty Liver Disease}

Other factors that could contribute to increased risk of development of HCC after DAA treatment are underlying metabolic associated fatty liver diseases, such as nonalcoholic fatty liver disease (NAFLD), as well as its more progressed clinical manifestation, nonalcoholic steatohepatitis (NASH). The impact of liver steatosis on HCV-related outcomes was summarized in a recent review [45], showing that liver steatosis has severe consequences, including a higher risk of liver fibrosis and HCC. Peleg et al. identified liver steatosis as a major risk factor of all-cause mortality and HCC in HCV patients who achieved a sustained virological response following DAA treatment, regardless of the stage of liver fibrosis [46]. Similarly, a recent study revealed that the underlying NAFLD is strongly associated with higher incidence of HCC in HCV patients after DAA treatment [38]. Indeed, growing evidence suggests that successful DAA treatments may cause modulations in lipid profile, ameliorate hepatic steatosis, reduce the incidence of metabolic alterations, including diabetes mellitus and insulin resistance, and improve the risk of cardiovascular disease [47].

\subsection{Genetic Variants}

A recent study by Degasperi et al. identified the genetic risk score (GRS) associated with hepatic fat content, as an independent predictive factor for de novo HCC in cirrhotic $\mathrm{HCV}$ patients treated by DAA. GRS includes selected variants in four major genes associated with hepatic steatosis and HCC: patatin-like phospholipase domain containing protein 3 (PNPLA3), transmembrane 6 superfamily member 2 (TM6SF2), membrane bound O-acyltransferase domain containing 7 (MBOAT7), and glucokinase regulator (GCKR). Interestingly, single genetic risk variants were not linked to HCC incidence in this study [48].

\subsection{Epigenetic Changes}

The epigenetic regulation of a gene is a highly complex process, by which the activity of a specific gene can be controlled by the structure of nearby chromatin. Although $\mathrm{HCV}$ is not incorporated into the host genome, it dysregulates the DNA methylation and modifies histone proteins, as summarized recently [49]. These epigenetic alterations play their part in liver carcinogenesis, including its initiation and progression. Hamdane et al. revealed that chronic HCV infection induces specific genome-wide alterations in H3K27ac that are associated with modifications in expression of mRNAs and proteins. Importantly, these alterations persisted, even after virus eradication with DAA treatment, and were associated with HCC risk [3].

Similarly, another study by Perez et al. revealed a profile of epigenetic alterations induced by HCV, including significant modulations in the active chromatin markers H3K9Ac and H3K4Me3, as well as in the silent chromatin marker H3K9Me3. The authors demon- 
strated that even these epigenetic changes remained present as an 'HCV-induced epigenetic signature' after virus eradication with DAA treatment and are associated with the development of HCC [50]. Thus, such persistent epigenetic alterations after DAA treatment provide a possibility to serve as biomarkers for risk of HCC development and as new potential therapeutic targets, to erase the HCC-associated gene expression signature.

\subsection{Immunological Biomarkers}

Chronic HCV, as well as other chronic infections, cause a significant deterioration of the host's immune system. Thanks to the DAA cure, it is now possible to understand how a long-lasting chronic infection modulates the immune system, which alterations persist after $\mathrm{HCV}$ elimination, and the immune system's reinvigoration capacity after HCV infection. A recent review comprehensively summarized observations from various immune cells during and after chronic $\mathrm{HCV}$ infection clearance, showing that many imprints of chronic $\mathrm{HCV}$ infection in diverse immune subpopulations, including features of immune exhaustion, persist for years, despite HCV elimination [51,52]. Thus, today, it is clear that a long-term $\mathrm{HCV}$ chronic infection causes irreversible damage to the immune system. Intrahepatic chronic inflammation in the liver has a tumor-promoting effect and deregulates innate and adaptive immune responses, contributing to cancer cell survival, proliferation, and migration. Therefore, it is highly likely that de novo HCC development and recurrence after DAA treatment is directly linked to $\mathrm{HCV}$-induced dysregulation of the antitumor immune function, even long after HCV eradication.

The recovery or normalization of some immune cell functions after DAA treatment has been reported. For instance, Jiang et al. revealed that the functions of circulating natural killer (NK) cells are normalized rapidly, during and after DAA treatment, and are similar to healthy controls [53]. However, such a decrease in the cytotoxic function of NK cells by DAA may attenuate the anti-tumor power of these cells. In parallel, the frequencies of circulating regulatory T cells (Tregs) stay high even long after the end of DAA therapy, which may significantly contribute to the immunosuppressive environment and hamper the anti-tumor immune response, as reviewed recently [52]. Other $\mathrm{T}$ cell populations stay poorly functional and do not consistently recover after HCV eradication [54,55]. Therefore, specific $\mathrm{HCV}$ alterations of the immune system can serve as predictive factors of de novo occurrence or recurrence of HCC after DAA treatment.

In 2018, one of the first studies revealed the possible immune-related differences of patients who later developed HCC as either de novo or as HCC recurrence after DAA treatment, compared to patients who did not develop HCC. The authors demonstrated that chronic HCV patients who would later develop HCC probably already had a specific immune profile before the start of DAA treatment, in particular higher serum levels of multiple immune mediators (IL-3, IL-21, IL-22, VEGF, TRAIL, APRIL, TWEAK, SCF, and MIG) [56], when compared to DAA-treated patients who did not develop HCC after therapy.

Another study recently reported significantly higher levels of IL-13 and IL-4 in HCV patients who developed de novo HCC following DAA treatment. In this study, all patients with a history of HCC before DAA treatment were excluded from analyses. HCV-infected patients treated with DAA were analyzed before treatment and followed up for 4 years. Patients who developed de novo HCC following DAA treatment were compared to matched control patients that were selected based on DAA treatment, sex, age, fibrosis status, and platelet counts. As significant differences in IL-13 and IL-4 were observed, before DAA treatment, this study validates the existence of a specific immune-related profile in patients who develop de novo HCC after DAA-induced virus eradication [57].

\subsection{Predictive Models and Scores}

The integrated predictive models combine different markers to better identify patients likely to develop cancer. In 2018, Ioannou et al. published one of the first predictive models that help to estimate HCC risk after DAA treatment [58]. The models included cirrhosis 
status, achievement of sustained virological response, age, platelet count, serum albumin, and aspartate aminotransferase versus alanine aminotransferase ratio. A recent study constructed a model based on albumin-bilirubin score, platelet count, and the presence of diabetes mellitus, to predict the risk of HCC occurrence after HCV eradication [59]. Similarly, Innes et al. identified a predictive model based on age, male sex, albuminbilirubin score and platelet count as the best-performing model to predict HCC risk among cirrhotic patients after HCV treatment [60]. Another study, from Tani et al., used a simple scoring system based on age of HCV patients and AFP level after DAA treatment to select patients with a high risk of HCC development [61]. Finally, a prediction model combining body mass index, FIB-4, and albumin and AFP level at sustained virological response time points was recently proposed as an efficient surveillance strategy for HCC occurrence after DAA treatment [62].

\section{Conclusions}

DAA treatment among $\mathrm{HCV}$-infected patients reduces risk but does not completely prevent the development of de novo HCC, while the risk of HCC recurrence seems to be almost unaffected by viral clearance. Although cirrhotic HCV patients are at higher risk of developing HCC after DAA treatment, HCC may also develop in livers with mild to moderate fibrosis. This indicates that multiple factors, including metabolic, genetic, epigenetic, and immune alterations, are crucial in determining the onset of HCC or its recurrence after $\mathrm{HCV}$ eradication.

In line with these findings, it is important to classify chronically HCV infected patients as being at risk for HCC development and to implement efficient follow-ups for them after HCV eradication. Predictive factors and specific circulating biomarkers for risk of development of HCC after DAA treatment are greatly needed, to improve the clinical management of chronic HCV patients prior to HCC development. The combination of clinical, biological, genetic, and immune predictors will lead to improved HCC risk stratification.

In the longer term, achieving HCV elimination worldwide seems unlikely, despite effective treatments. Moreover, patients remain at risk of reinfection even after successful treatment. As DAA treatment among HCV-infected patients does not completely prevent the development of HCC, HCV-related HCC will not disappear until the successful development and global use of an efficient $\mathrm{HCV}$ vaccine. Indeed, the prevention of $\mathrm{HCV}$ through vaccination would be the best strategy to prevent the eventual development of HCC related to this virus.

Author Contributions: Conceptualization, Z.M.J.; writing—original draft preparation, Z.M.J., K.S.; writing—review and editing, Z.M.J., S.A., T.D.; visualization, K.S., Z.M.J.; funding acquisition, Z.M.J., S.A., T.D. All authors have read and agreed to the published version of the manuscript.

Funding: This work was supported by the MEAE and the MESRI as part of Franco-Pakistani Hubert Curien Partnership, grant number 43289YG.

Institutional Review Board Statement: Not applicable.

Informed Consent Statement: Not applicable.

Data Availability Statement: Not applicable.

Conflicts of Interest: The authors declare no conflict of interest.

\section{References}

1. Sung, H.; Ferlay, J.; Siegel, R.L.; Laversanne, M.; Soerjomataram, I.; Jemal, A.; Bray, F. Global Cancer Statistics 2020: GLOBOCAN Estimates of Incidence and Mortality Worldwide for 36 Cancers in 185 Countries. CA A Cancer J. Clin. 2021, 71, 209-249. [CrossRef]

2. Hirano, J.; Yoshio, S.; Sakai, Y.; Songling, L.; Suzuki, T.; Itoh, Y.; Zhang, H.; Chen, D.V.; Haga, S.; Oomori, H.; et al. Hepatitis C virus modulates signal peptide peptidase to alter host protein processing. Proc. Natl. Acad. Sci. USA 2021, 118 , e2026184118. [CrossRef] [PubMed] 
3. Hamdane, N.; Jühling, F.; Crouchet, E.; El Saghire, H.; Thumann, C.; Oudot, M.A.; Bandiera, S.; Saviano, A.; Ponsolles, C.; Roca Suarez, A.A.; et al. HCV-Induced Epigenetic Changes Associated with Liver Cancer Risk Persist After Sustained Virologic Response. Gastroenterology 2019, 156, 2313-2329.e7. [CrossRef] [PubMed]

4. Rios, D.A.; Casciato, P.C.; Caldirola, M.S.; Gaillard, M.I.; Giadans, C.; Ameigeiras, B.; De Matteo, E.N.; Preciado, M.V.; Valva, P. Chronic Hepatitis C Pathogenesis: Immune Response in the Liver Microenvironment and Peripheral Compartment. Front. Cell. Infect. Microbiol. 2021, 11. [CrossRef] [PubMed]

5. Macek Jilkova, Z.; Afzal, S.; Marche, H.; Decaens, T.; Sturm, N.; Jouvin-Marche, E.; Huard, B.; Marche, P.N. Progression of fibrosis in patients with chronic viral hepatitis is associated with IL-17(+) neutrophils. Liver Int. Off. J. Int. Assoc. Study Liver 2016, 36, 1116-1124. [CrossRef]

6. Fugier, E.; Marche, H.; Thelu, M.A.; Macek Jilkova, Z.; Van Campenhout, N.; Dufeu-Duchesne, T.; Leroy, V.; Zarski, J.P.; Sturm, N.; Marche, P.N.; et al. Functions of liver natural killer cells are dependent on the severity of liver inflammation and fibrosis in chronic hepatitis C. PLoS ONE 2014, 9, e95614. [CrossRef] [PubMed]

7. Petruzziello, A.; Marigliano, S.; Loquercio, G.; Cozzolino, A.; Cacciapuoti, C. Global epidemiology of hepatitis C virus infection: An up-date of the distribution and circulation of hepatitis C virus genotypes. World J. Gastroenterol. 2016, 22, 7824-7840. [CrossRef]

8. Choo, Q.-L.; Kuo, G.; Weiner, A.J.; Overby, L.R.; Bradley, D.W.; Houghton, M. Isolation of a cDNA cLone Derived from a Blood-Borne Non-A, Non-B Viral Hepatitis Genome. Science 1989, 244, 359-362. [CrossRef]

9. Ghany, M.G.; Lok, A.S.F.; Dienstag, J.L.; Feinstone, S.M.; Hoofnagle, J.H.; Jake Liang, T.; Seeff, L.B.; Cohen, D.E.; Bezerra, J.A.; Chung, R.T. The 2020 Nobel Prize for Medicine or Physiology for the Discovery of Hepatitis C Virus: A Triumph of Curiosity and Persistence. Hepatology 2021, 74, 2813-2823. [CrossRef]

10. Nahon, P.; Layese, R.; Bourcier, V.; Cagnot, C.; Marcellin, P.; Guyader, D.; Pol, S.; Larrey, D.; De Ledinghen, V.; Ouzan, D.; et al. Incidence of Hepatocellular Carcinoma After Direct Antiviral Therapy for HCV in Patients with Cirrhosis Included in Surveillance Programs. Gastroenterology 2018, 155, 1436-1450.e6. [CrossRef]

11. Kanwal, F.; Kramer, J.R.; Asch, S.M.; Cao, Y.; Li, L.; El-Serag, H.B. Long-Term Risk of Hepatocellular Carcinoma in HCV Patients Treated with Direct Acting Antiviral Agents. Hepatology 2020, 71, 44-55. [CrossRef]

12. Rinaldi, L.; Nevola, R.; Franci, G.; Perrella, A.; Corvino, G.; Marrone, A.; Berretta, M.; Morone, M.V.; Galdiero, M.; Giordano, M.; et al. Risk of Hepatocellular Carcinoma after HCV Clearance by Direct-Acting Antivirals Treatment Predictive Factors and Role of Epigenetics. Cancers 2020, 12, 1351. [CrossRef]

13. Ioannou, G.N.; Green, P.K.; Berry, K. HCV eradication induced by direct-acting antiviral agents reduces the risk of hepatocellular carcinoma. J. Hepatol. 2018, 68, 32-53. [CrossRef]

14. Frazzoni, L.; Sikandar, U.; Metelli, F.; Sadalla, S.; Mazzella, G.; Bazzoli, F.; Fuccio, L.; Azzaroli, F. Hepatocellular Carcinoma Recurrence after Hepatitis C Virus Therapy with Direct-Acting Antivirals. A Systematic Review and Meta-Analysis. J. Clin. Med. 2021, 10, 1694. [CrossRef]

15. Compagnoni, S.; Bruno, E.M.; Madonia, G.; Cannizzaro, M.; Madonia, S. Direct antiviral agents in hepatitis C virus related liver disease: Don't count the chickens before they're hatched. World J. Gastroenterol. 2021, 27, 2771-2783. [CrossRef] [PubMed]

16. Romano, A.; Angeli, P.; Piovesan, S.; Noventa, F.; Anastassopoulos, G.; Chemello, L.; Cavalletto, L.; Gambato, M.; Russo, F.P.; Burra, P.; et al. Newly diagnosed Hepatocellular Carcinoma in patients with advanced hepatitis C treated with DAAs: A prospective population study. J. Hepatol. 2018, 69, 345-352. [CrossRef]

17. Carrat, F.; Fontaine, H.; Dorival, C.; Simony, M.; Diallo, A.; Hezode, C.; De Ledinghen, V.; Larrey, D.; Haour, G.; Bronowicki, J.P.; et al. Clinical outcomes in patients with chronic hepatitis $\mathrm{C}$ after direct-acting antiviral treatment: A prospective cohort study. Lancet 2019, 393, 1453-1464. [CrossRef]

18. Kanwal, F.; Kramer, J.; Asch, S.M.; Chayanupatkul, M.; Cao, Y.; El-Serag, H.B. Risk of Hepatocellular Cancer in HCV Patients Treated with Direct-Acting Antiviral Agents. Gastroenterology 2017, 153, 996-1005.e1001. [CrossRef] [PubMed]

19. Imai, K.; Takai, K.; Hanai, T.; Suetsugu, A.; Shiraki, M.; Shimizu, M. Sustained virological response by direct-acting antivirals reduces the recurrence risk of hepatitis C-related hepatocellular carcinoma after curative treatment. Mol. Clin. Oncol. 2020, 12, 111-116. [CrossRef]

20. Calvaruso, V.; Cabibbo, G.; Cacciola, I.; Petta, S.; Madonia, S.; Bellia, A.; Tine, F.; Distefano, M.; Licata, A.; Giannitrapani, L.; et al. Incidence of Hepatocellular Carcinoma in Patients With HCV-Associated Cirrhosis Treated with Direct-Acting Antiviral Agents. Gastroenterology 2018, 155, 411-421.e4. [CrossRef]

21. Ooka, Y.; Miho, K.; Shuntaro, O.; Nakamura, M.; Ogasawara, S.; Suzuki, E.; Yasui, S.; Chiba, T.; Arai, M.; Kanda, T.; et al. Prediction of the very early occurrence of HCC right after DAA therapy for HCV infection. Hepatol. Int. 2018, 12, 523-530. [CrossRef]

22. Mariño, Z.; Darnell, A.; Lens, S.; Sapena, V.; Díaz, A.; Belmonte, E.; Perelló, C.; Calleja, J.L.; Varela, M.; Rodriguez, M.; et al. Time association between hepatitis $C$ therapy and hepatocellular carcinoma emergence in cirrhosis: Relevance of non-characterized nodules. J. Hepatol. 2019, 70, 874-884. [CrossRef]

23. Degasperi, E.; D’Ambrosio, R.; Iavarone, M.; Sangiovanni, A.; Aghemo, A.; Soffredini, R.; Borghi, M.; Lunghi, G.; Colombo, M.; Lampertico, P. Factors Associated with Increased Risk of De Novo or Recurrent Hepatocellular Carcinoma in Patients with Cirrhosis Treated with Direct-Acting Antivirals for HCV Infection. Clin. Gastroenterol. Hepatol. Off. Clin. Pract. J. Am. Gastroenterol. Assoc. 2019, 17, 1183-1191.e1187. [CrossRef] [PubMed] 
24. Ogawa, E.; Nomura, H.; Nakamuta, M.; Furusyo, N.; Kajiwara, E.; Dohmen, K.; Kawano, A.; Ooho, A.; Azuma, K.; Takahashi, K.; et al. Development of Hepatocellular Carcinoma by Patients Aged 75-84 with Chronic Hepatitis C Treated with Direct-acting Antivirals. J. Infect. Dis. 2020. [CrossRef] [PubMed]

25. Watanabe, T.; Tokumoto, Y.; Joko, K.; Michitaka, K.; Horiike, N.; Tanaka, Y.; Tada, F.; Kisaka, Y.; Nakanishi, S.; Yamauchi, K.; et al. Sex difference in the development of hepatocellular carcinoma after direct-acting antiviral therapy in patients with HCV infection. J. Med. Virol. 2020. [CrossRef] [PubMed]

26. Ebrahimi, H.; Naderian, M.; Sohrabpour, A.A. New Concepts on Reversibility and Targeting of Liver Fibrosis; A Review Article. Middle East J. Dig. Dis. 2018, 10, 133-148. [CrossRef] [PubMed]

27. Ravaioli, F.; Conti, F.; Brillanti, S.; Andreone, P.; Mazzella, G.; Buonfiglioli, F.; Serio, I.; Verrucchi, G.; Bacchi Reggiani, M.L.; Colli, A.; et al. Hepatocellular carcinoma risk assessment by the measurement of liver stiffness variations in HCV cirrhotics treated with direct acting antivirals. Dig. Liver Dis. Off. J. Ital. Soc. Gastroenterol. Ital. Assoc. Study Liver 2018, 50, 573-579. [CrossRef]

28. Rinaldi, L.; Guarino, M.; Perrella, A.; Pafundi, P.C.; Valente, G.; Fontanella, L.; Nevola, R.; Guerrera, B.; Iuliano, N.; Imparato, M.; et al. Role of Liver Stiffness Measurement in Predicting HCC Occurrence in Direct-Acting Antivirals Setting: A Real-Life Experience. Dig. Dis. Sci. 2019, 64, 3013-3019. [CrossRef] [PubMed]

29. Rinaldi, L.; Perrella, A.; Guarino, M.; De Luca, M.; Piai, G.; Coppola, N.; Pafundi, P.C.; Ciardiello, F.; Fasano, M.; Martinelli, E.; et al. Incidence and risk factors of early HCC occurrence in HCV patients treated with direct acting antivirals: A prospective multicentre study. J. Transl. Med. 2019, 17, 292. [CrossRef] [PubMed]

30. Ogasawara, N.; Saitoh, S.; Akuta, N.; Sezaki, H.; Suzuki, F.; Fujiyama, S.; Kawamura, Y.; Hosaka, T.; Kobayashi, M.; Suzuki, Y.; et al. Advantage of liver stiffness measurement before and after direct-acting antiviral therapy to predict hepatocellular carcinoma and exacerbation of esophageal varices in chronic hepatitis C. Hepatol. Res. Off. J. Jpn. Soc. Hepatol. 2020, 50, 426-438. [CrossRef]

31. Alonso Lopez, S.; Manzano, M.L.; Gea, F.; Gutierrez, M.L.; Ahumada, A.M.; Devesa, M.J.; Olveira, A.; Polo, B.A.; Marquez, L.; Fernandez, I.; et al. A Model Based on Noninvasive Markers Predicts Very Low Hepatocellular Carcinoma Risk After Viral Response in Hepatitis C Virus-Advanced Fibrosis. Hepatology 2020, 72, 1924-1934. [CrossRef]

32. Pons, M.; Rodríguez-Tajes, S.; Esteban, J.I.; Mariño, Z.; Vargas, V.; Lens, S.; Buti, M.; Augustin, S.; Forns, X.; Mínguez, B.; et al. Non-invasive prediction of liver-related events in patients with $\mathrm{HCV}$-associated compensated advanced chronic liver disease after oral antivirals. J. Hepatol. 2020, 72, 472-480. [CrossRef]

33. You, M.W.; Kim, K.W.; Shim, J.J.; Pyo, J. Impact of liver-stiffness measurement on hepatocellular carcinoma development in chronic hepatitis $C$ patients treated with direct-acting antivirals: A systematic review and time-to-event meta-analysis. $J$. Gastroenterol. Hepatol. 2021, 36, 601-608. [CrossRef] [PubMed]

34. Ioannou, G.N.; Beste, L.A.; Green, P.K.; Singal, A.G.; Tapper, E.B.; Waljee, A.K.; Sterling, R.K.; Feld, J.J.; Kaplan, D.E.; Taddei, T.H.; et al. Increased Risk for Hepatocellular Carcinoma Persists Up to 10 Years After HCV Eradication in Patients with Baseline Cirrhosis or High FIB-4 Scores. Gastroenterology 2019, 157, 1264-1278.e1264. [CrossRef]

35. Ioannou, G.N. HCC surveillance after SVR in patients with F3/F4 fibrosis. J. Hepatol. 2021, 74, 458-465. [CrossRef] [PubMed]

36. Tanaka, Y.; Ogawa, E.; Huang, C.F.; Toyoda, H.; Jun, D.W.; Tseng, C.H.; Hsu, Y.C.; Enomoto, M.; Takahashi, H.; Furusyo, N.; et al. HCC risk post-SVR with DAAs in East Asians: Findings from the REAL-C cohort. Hepatol. Int. 2020, 14, 1023-1033. [CrossRef]

37. Watanabe, T.; Tokumoto, Y.; Joko, K.; Michitaka, K.; Horiike, N.; Tanaka, Y.; Tada, F.; Kisaka, Y.; Nakanishi, S.; Yamauchi, K.; et al. AFP and eGFR are related to early and late recurrence of HCC following antiviral therapy. BMC Cancer 2021, 21, 699. [CrossRef] [PubMed]

38. Ji, D.; Chen, G.F.; Niu, X.X.; Zhang, M.; Wang, C.; Shao, Q.; Wu, V.; Wang, Y.; Cheng, G.; Hurwitz, S.J.; et al. Non-alcoholic fatty liver disease is a risk factor for occurrence of hepatocellular carcinoma after sustained virologic response in chronic hepatitis $\mathrm{C}$ patients: A prospective four-years follow-up study. Metab. Open 2021, 10, 100090. [CrossRef]

39. Yoshimasu, Y.; Furuichi, Y.; Kasai, Y.; Takeuchi, H.; Sugimoto, K.; Nakamura, I.; Itoi, T. Predictive factors for hepatocellular carcinoma occurrence or recurrence after direct-acting antiviral agents in patients with chronic hepatitis C. J. Gastrointest. Liver Dis. 2019, 28, 63-71. [CrossRef]

40. Yasui, Y.; Kurosaki, M.; Komiyama, Y.; Takada, H.; Tamaki, N.; Watakabe, K.; Okada, M.; Wang, W.; Shimizu, T.; Kubota, Y.; et al. Wisteria floribunda agglutinin-positive Mac-2 binding protein predicts early occurrence of hepatocellular carcinoma after sustained virologic response by direct-acting antivirals for hepatitis C virus. Hepatol. Res. Off. J. Jpn. Soc. Hepatol. 2018, 48, 1131-1139. [CrossRef]

41. Mucke, V.T.; Thomas, D.; Mucke, M.M.; Waidmann, O.; Zeuzem, S.; Sarrazin, C.; Pfeilschifter, J.; Vermehren, J.; Finkelmeier, F.; Grammatikos, G. Serum sphingolipids predict de novo hepatocellular carcinoma in hepatitis C cirrhotic patients with sustained virologic response. Liver Int. Off. J. Int. Assoc. Study Liver 2019, 39, 2174-2183. [CrossRef]

42. Faillaci, F.; Marzi, L.; Critelli, R.; Milosa, F.; Schepis, F.; Turola, E.; Andreani, S.; Vandelli, G.; Bernabucci, V.; Lei, B.; et al. Liver Angiopoietin-2 Is a Key Predictor of De Novo or Recurrent Hepatocellular Cancer After Hepatitis C Virus Direct-Acting Antivirals. Hepatology 2018, 68, 1010-1024. [CrossRef] [PubMed]

43. Ramadan, H.K.; Meghezel, E.M.; Abdel-Malek, M.O.; Askar, A.A.; Hetta, H.F.; Mahmoud, A.A.; Abdel-Aal, A.M. Correlation Between Vascular Endothelial Growth Factor and Long-Term Occurrence of HCV-Related Hepatocellular Carcinoma After Treatment with Direct-Acting Antivirals. Cancer Investig. 2021, 39, 653-660. [CrossRef] [PubMed] 
44. Pascut, D.; Cavalletto, L.; Pratama, M.Y.; Bresolin, S.; Trentin, L.; Basso, G.; Bedogni, G.; Tiribelli, C.; Chemello, L. Serum miRNA Are Promising Biomarkers for the Detection of Early Hepatocellular Carcinoma after Treatment with Direct-Acting Antivirals. Cancers 2019, 11, 1773. [CrossRef]

45. Siphepho, P.Y.; Liu, Y.T.; Shabangu, C.S.; Huang, J.F.; Huang, C.F.; Yeh, M.L.; Yu, M.L.; Wang, S.C. The Impact of Steatosis on Chronic Hepatitis C Progression and Response to Antiviral Treatments. Biomedicines 2021, 9, 1491. [CrossRef] [PubMed]

46. Peleg, N.; Issachar, A.; Sneh Arbib, O.; Cohen-Naftaly, M.; Harif, Y.; Oxtrud, E.; Braun, M.; Leshno, M.; Barsheshet, A.; Shlomai, A. Liver steatosis is a major predictor of poor outcomes in chronic hepatitis C patients with sustained virological response. J. Viral Hepat. 2019, 26, 1257-1265. [CrossRef]

47. Shengir, M.; Elgara, M.; Sebastiani, G. Metabolic and cardiovascular complications after virological cure in hepatitis C: What awaits beyond. World J. Gastroenterol. 2021, 27, 1959-1972. [CrossRef]

48. Degasperi, E.; Galmozzi, E.; Pelusi, S.; D'Ambrosio, R.; Soffredini, R.; Borghi, M.; Perbellini, R.; Facchetti, F.; Iavarone, M.; Sangiovanni, A.; et al. Hepatic Fat-Genetic Risk Score Predicts Hepatocellular Carcinoma in Patients with Cirrhotic HCV Treated with DAAs. Hepatology 2020, 72, 1912-1923. [CrossRef]

49. Domovitz, T.; Gal-Tanamy, M. Tracking down the Epigenetic Footprint of HCV-Induced Hepatocarcinogenesis. J. Clin. Med. 2021, 10, 551. [CrossRef]

50. Perez, S.; Kaspi, A.; Domovitz, T.; Davidovich, A.; Lavi-Itzkovitz, A.; Meirson, T.; Alison Holmes, J.; Dai, C.Y.; Huang, C.F.; Chung, R.T.; et al. Hepatitis $C$ virus leaves an epigenetic signature post cure of infection by direct-acting antivirals. PLoS Genet. 2019, 15, e1008181. [CrossRef] [PubMed]

51. Wedemeyer, H.; Khera, T.; Strunz, B.; Björkström, N.K. Reversal of Immunity after Clearance of Chronic HCV Infection-All Reset? Front. Immunol. 2020, 11, 2659. [CrossRef]

52. Ghosh, A.; Romani, S.; Kottilil, S.; Poonia, B. Lymphocyte Landscape after Chronic Hepatitis C Virus (HCV) Cure: The New Normal. Int. J. Mol. Sci. 2020, 21, 7473. [CrossRef]

53. Jiang, H.J.; Wang, X.X.; Luo, B.F.; Cong, X.; Jin, Q.; Qin, H.; Zhang, H.Y.; Kong, X.S.; Wei, L.; Feng, B. Direct antiviral agents upregulate natural killer cell potential activity in chronic hepatitis C patients. Clin. Exp. Med. 2019, 19, 299-308. [CrossRef] [PubMed]

54. Aregay, A.; Owusu Sekyere, S.; Deterding, K.; Port, K.; Dietz, J.; Berkowski, C.; Sarrazin, C.; Manns, M.P.; Cornberg, M.; Wedemeyer, $\mathrm{H}$. Elimination of hepatitis $\mathrm{C}$ virus has limited impact on the functional and mitochondrial impairment of HCVspecific CD8+ T cell responses. J. Hepatol. 2019, 71, 889-899. [CrossRef] [PubMed]

55. Hartnell, F.; Esposito, I.; Swadling, L.; Brown, A.; Phetsouphanh, C.; de Lara, C.; Gentile, C.; Turner, B.; Dorrell, L.; Capone, S.; et al. Characterizing Hepatitis C Virus-Specific CD4(+) T Cells Following Viral-Vectored Vaccination, Directly Acting Antivirals, and Spontaneous Viral Cure. Hepatology 2020, 72, 1541-1555. [CrossRef]

56. Debes, J.D.; van Tilborg, M.; Groothuismink, Z.M.A.; Hansen, B.E.; Schulze Zur Wiesch, J.; von Felden, J.; de Knegt, R.J.; Boonstra, A. Levels of Cytokines in Serum Associate with Development of Hepatocellular Carcinoma in Patients with HCV Infection Treated with Direct-Acting Antivirals. Gastroenterology 2018, 154, 515-517.e3. [CrossRef]

57. Macek Jilkova, Z.; Seigneurin, A.; Coppard, C.; Ouaguia, L.; Aspord, C.; Marche, P.N.; Leroy, V.; Decaens, T. Circulating IL-13 Is Associated with De Novo Development of HCC in HCV-Infected Patients Responding to Direct-Acting Antivirals. Cancers 2020, 12, 3820. [CrossRef] [PubMed]

58. Ioannou, G.N.; Green, P.K.; Beste, L.A.; Mun, E.J.; Kerr, K.F.; Berry, K. Development of models estimating the risk of hepatocellular carcinoma after antiviral treatment for hepatitis C. J. Hepatol. 2018, 69, 1088-1098. [CrossRef] [PubMed]

59. Abe, K.; Wakabayashi, H.; Nakayama, H.; Suzuki, T.; Kuroda, M.; Yoshida, N.; Tojo, J.; Kogure, A.; Rai, T.; Saito, H.; et al. Factors associated with hepatocellular carcinoma occurrence after HCV eradication in patients without cirrhosis or with compensated cirrhosis. PLoS ONE 2020, 15, e0243473. [CrossRef]

60. Innes, H.; Jepsen, P.; McDonald, S.; Dillon, J.; Hamill, V.; Yeung, A.; Benselin, J.; Went, A.; Fraser, A.; Bathgate, A.; et al. Performance of models to predict hepatocellular carcinoma risk among UK patients with cirrhosis and cured HCV infection. JHEP Rep. 2021, 3, 100384. [CrossRef] [PubMed]

61. Tani, J.; Morishita, A.; Sakamoto, T.; Takuma, K.; Nakahara, M.; Fujita, K.; Oura, K.; Tadokoro, T.; Mimura, S.; Nomura, T.; et al. Simple scoring system for prediction of hepatocellular carcinoma occurrence after hepatitis $\mathrm{C}$ virus eradication by direct-acting antiviral treatment: All Kagawa Liver Disease Group Study. Oncol. Lett. 2020, 19, 2205-2212. [CrossRef] [PubMed]

62. Tahata, Y.; Sakamori, R.; Yamada, R.; Kodama, T.; Hikita, H.; Hagiwara, H.; Imai, Y.; Hiramatsu, N.; Tamura, S.; Yamamoto, K.; et al. Prediction model for hepatocellular carcinoma occurrence in patients with hepatitis $\mathrm{C}$ in the era of direct-acting anti-virals. Aliment. Pharmacol. Ther. 2021, 54, 1340-1349. [CrossRef] [PubMed] 